\title{
Exposure to active and passive smoking among Greek pregnant women
}

\author{
Victoria G. Vivilaki ${ }^{1 *}$, Athina Diamanti ${ }^{1,2}$, Maria Tzeli ${ }^{1}$, Evridiki Patelarou ${ }^{3}$, Debra Bick ${ }^{3}$, Sophia Papadakis ${ }^{4}$,
} Katerina Lykeridou ${ }^{1}$ and Paraskevi Katsaounou ${ }^{5}$

\begin{abstract}
Background: Active smoking and exposure to passive smoke are responsible for numerous adverse pregnancy outcomes for women and their infants. The aim of this study was to explore the perceptions, attitudes, patterns of personal tobacco use and exposure to environmental smoke among a sample of pregnant women in Greece.

Method: A cross sectional survey was undertaken of 300 women identified from the perinatal care records of the Maternity Departments of two hospitals in Athens between February 2013 and May 2013. Data on active and passive maternal smoking status in the first, second, and third trimesters of pregnancy, fetal and neonatal tobacco related complications, exposure to environmental tobacco smoke during pregnancy, quit attempts, behaviors towards avoiding passive smoking and beliefs towards smoking cessation during pregnancy were collected using self-administered questionnaires on the 3rd postnatal day. Women also completed the Edinburgh Postnatal Depression Scale (EPDS).

Results: Of 300 women recruited to the study $48 \%$ reported tobacco use during the first trimester of pregnancy. Amongst participants who were tobacco users, $83.3 \%$ reported making an attempt to quit but less than half (45.1\%) were successful. Among women who continued to smoke during pregnancy the majority (55.8\%) reported that they felt unable to quit, and $9.3 \%$ reported that they considered smoking cessation was not an important health issue for them. Participants who continued to smoke during pregnancy were more likely to report fetal $\left(x_{2}=11.41 ; \mathrm{df}=5 ; p<0.05\right)$ and newborn complications $(x 2=6.41 ; \mathrm{df}=2 ; p<0.05)$, including preterm birth and low birth weight. Participants who reported that their partners were smokers were more likely to smoke throughout their pregnancy $(X 2=14.62 ; \mathrm{df}=1$; $p<0.001$ ). High rates of second-hand smoke exposure were reported among both smoking and non-smoking women. Pregnant smokers had significantly higher levels of postnatal depressive and anxiety symptomatology, as measured using the EPDS, than non-smokers.

Conclusion: Our data supports the importance of ensuring that pregnant women, their partners and close relatives are educated on the health risks of active and passive smoking and how these could have an adverse effect to their fetus and infants, as well as the pregnant women themselves.
\end{abstract}

Keywords: Tobacco smoking in pregnancy, Health behaviour, Environmental tobacco smoke, Smoking cessation, Pregnancy complication, Midwives

\footnotetext{
*Correspondence: v_vivilaki@yahoo.co.uk

${ }^{1}$ Department of Midwifery, Technological Educational Institution of Athens, Athens, Greece

Full list of author information is available at the end of the article
} 


\section{Background}

Eliminating active and passive maternal tobacco smoking during pregnancy are among the most important interventions to reduce the risk of adverse birth outcomes [1-5]. Previous studies have reported that tobacco smoking during pregnancy is significantly associated with increased risks of intrauterine growth retardation, preterm birth, low birth weight, miscarriage, stillbirth, congenital malformation, sudden infant death syndrome, geneticrelated hereditary diseases, perinatal mortality and morbidity, short stature, cognitive delays, and neurologic disorders [2-9]. Pregnant women who smoke place themselves and their infants in a high-risk situation [2]. However, more than a third of women smokers will continue to smoke during pregnancy, despite being aware of many of the imminent risks to their infants [10].

Previous studies have demonstrated that pregnant smokers usually have partners who actively smoked during pregnancy $[8,11,12]$. The health of pregnant women and their fetuses' is inherently threatened by both the active and passive smoking of the pregnant women's partners or families [2, 12]. However, the effect of passive maternal smoking is not explicit enough and has not been extensively studied $[9,13,14]$. The perceptions of pregnant smokers regarding the health risks of smoking and the need to abstain from passive smoking have been described as important factors influencing a smoke-free behavior [2, 8]. A partner who continues using tobacco throughout a woman's pregnancy is a significant prognostic factor of the current smoking status of the pregnant woman $[2,11,15]$.

Recent studies have generally highlighted the need to conduct further research on the types of interventions which could be employed in order to set goals for reducing smoking in pregnancy and promote smoke-free environments, as a potential benchmark of an effective primary care system [16]. Midwives and other community health professionals need to educate, and offer support to pregnant women to stop smoking and avoid postnatal relapse among woman who have quit smoking during their pregnancy [17]. Despite the fact that pregnancy provides a 'window of opportunity' to encourage positive behavior change, encouraging pregnant smokers to change their health behavior may be challenging [3].

The aim of this study was to explore the perceptions, attitudes and behaviors towards active and passive maternal smoking during pregnancy of smokers, nonsmokers and recent quitters in Athens, Greece. Our specific objectives were to: i) assess the proportion of women who were active smokers and exposed to second-hand smoking during pregnancy; ii) compare pregnant smokers and non-smokers in regards to postnatal depressive and anxiety symptomatology, neonatal problems, partner smoking habits and other sources of passive smoking (work, social places, car etc.); and iii) explore women's perceptions and attitudes towards smoking during the perinatal period.

\section{Methods \\ Instruments}

A self-administered questionnaire was developed to collect baseline socio-demographic data from women on their total household income, employment status, ethnicity and age at which full-time education was completed. In addition, women's reproductive history was also recorded, including history of previous miscarriage or pregnancy termination, family planning, type of birth and antenatal/postnatal complications, attitudes toward tobacco smoking, perceived health risk, smoking history, smoking volume (before and during the index pregnancy) and exposure to passive smoking during the index pregnancy.

\section{Edinburgh postnatal depression scale (EPDS)}

The Edinburgh Postnatal Depression Scale (EPDS) [18] is a ten item self-report scale, consisting of statements describing depressive and anxiety symptoms experienced during the last 7 days, which can be administered at any stage following birth [19]. High EPDS scores in the first week of birth could identify women with low mood or postnatal 'blues', a transient psychological condition, which some studies have identified as a potential indicator of postnatal depression if symptoms persist [20]. Each item is scored on a point scale ranging from 0 to 3 , depending on the severity or duration of each symptom. The Greek version of the EPDS used in this study was validated and demonstrated high internal consistency (Chronbach's alpha $=0.804$ and Guttman split-half coefficient 0.742 ). The Greek EPDS was significantly correlated (Pearson $r=0.66 p<0.0005$ ) to the validated Greek version of BDI-II (Beck Depression Inventory II) [21]. A threshold score of $8 / 9$ fitted the model sensitivity at $76.7 \%$ and model specificity at $68.3 \%$ [22].

\section{Setting, sampling and target population}

Following the pilot testing of the smoking habits questionnaire using a focus-group method, the questionnaire was administered to women who gave birth during February 2013 to May 2013 inclusive who were inpatients on the postnatal wards of two public maternity hospitals in Athens. Women were asked to complete the questionnaires on their 3rd postnatal day. Women were considered eligible to take part in the study if they met the following criteria: (1) aged 16 to 45 years; (2) fluent in spoken and written Greek; (3) healthy mother and infant following the birth; and (4) able to provide informed consent. 


\section{Participants and data collection}

A total of 337 women were identified as eligible from the perinatal care records of the two maternity units (Fig. 1). The midwife-researchers (VV, MT) ensured there was a balance in recruitment using a calendar to recruit participants across different shifts and days of the week. More specifically, the women were recruited on a one-day a week basis in both sites (i.e. first week on a Monday, the following week on a Tuesday, the week following that on a Wednesday, etc.). This technique was employed in order to avoid bias associated with possible seasonality of smoking habits. Each recruitment day was split into three shifts (8 a.m., 4 p.m., 12 a.m.), and the first four women who had given birth after 8 a.m. were selected on one week and likewise, the first four who had given birth the following week after 4 p.m. were also selected. This ensured the reduction of possible bias related to the time of smoking.

Women were encouraged to discuss any concerns they had about their smoking status with the research midwives. In these cases women were advised that their ward and/or community midwife would be informed of their responses to the screens for smoking status, in order to refer the women to s smoking cessation support services if they wished to quit. All participants were informed verbally by the research midwives about smoking

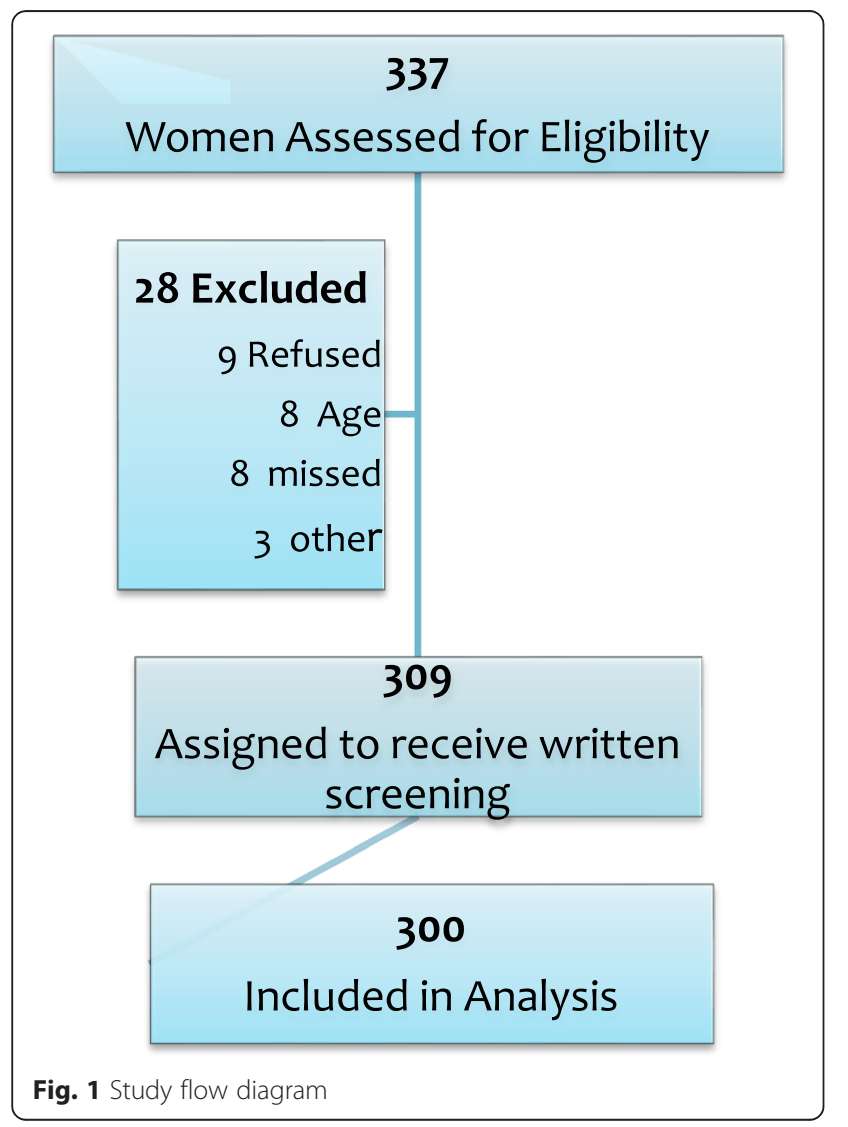

cessation health services available in the community to support them postnatally.

The research ethics boards of both hospitals approved the study (reference number \#113/9-5-2012). All participants provided oral informed consent prior to enrolment. Included with the questionnaires was a cover letter explaining the purpose of the study, providing the researchers' details and contact information, and clearly stating that all answers would be confidential and no names would ever be used in any reports presenting the study findings.

\section{Data analysis}

Statistical analysis was performed using IBM SPSS Statistics version 20.0 and LISREL (Linear Structural Relations). The descriptive characteristics were calculated for the socio-demographic variables. The assumptions of normality, homogeneity and independent cases of the sample were checked. We used chi-square tests to investigate whether significant differences existed in maternal beliefs and attitudes toward smoking during pregnancy between groups of quitters and smokers. T-tests were carried out to compare the descriptive variables, risk perception, attitudes to smoking, smoking behaviors women who smoked during pregnancy. Reliability coefficients, as measured by Cronbach's alpha, were calculated for the smoking questionnaire in order to assess reproducibility and consistency of the instrument; and the internal consistency of the questionnaire was also tested using Guttman split-half coefficients.

\section{Results}

Sample characteristics

Of the 337 women initially approached, 300 consented to take part in the study, a participation rate of $89.0 \%$ (Fig. 1). The women had a mean age of 33.76 years (Standard Error of Mean, SEM 0.537, range 20-45 years). Socio-demographic characteristics are shown in Table 1, which indicates that $48 \%$ of the participants were smokers at pregnancy commencement. In total, $73.7 \%$ of the total sample reported being smoke-free during pregnancy. Among tobacco users, $83.3 \%$ tried to quit and less than half of participants (45.1\%) were successful. Twenty-two percent of women had quit during pregnancy and $26.3 \%$ of the participants continued to smoke during pregnancy. Among women who did not stop smoking during pregnancy, $55.8 \%$ claimed that they could not stop smoking, another $25.6 \%$ stated that they did not want to stop smoking and $9.3 \%$ of women claimed that they considered smoking cessation was not an important health issue for them. The harmful effects of smoking during pregnancy on the fetus $\left(\mathrm{X}^{2}=11.41 ; \mathrm{df}=\right.$ $5 ; p<0.05)$ and the newborn $(\mathrm{X} 2=6.41 ; \mathrm{df}=2 ; p<0.05)$ were confirmed in our study. The smoking status of the 
Table 1 Characteristics of the 300 pregnant women sample between February 2013 to May 2013

\begin{tabular}{|c|c|c|c|c|}
\hline & \multicolumn{3}{|c|}{ Smoking status during pregnancy } & \multirow[b]{2}{*}{$P$ value } \\
\hline & Smokers women $n(\%)$ & Non smokers women $n(\%)$ & Total n (\%) & \\
\hline \multicolumn{5}{|l|}{ Age } \\
\hline $16-20$ & $9(3)$ & $7(2.3)$ & $16(5.3)$ & \multirow[t]{4}{*}{0.502} \\
\hline $21-30$ & $63(21)$ & $60(20)$ & $123(41)$ & \\
\hline $31-40$ & $67(22.3)$ & $77(25.7)$ & $144(48)$ & \\
\hline$>40$ & $5(1.7)$ & $12(4)$ & $17(5.7)$ & \\
\hline \multicolumn{5}{|l|}{ Nationality } \\
\hline Greek & $129(43)$ & $126(42)$ & 255(85) & \multirow[t]{2}{*}{0.012} \\
\hline Other & 15(5) & $30(10)$ & $45(15)$ & \\
\hline \multicolumn{5}{|l|}{ Education } \\
\hline Elementary \& junior high & $6(2)$ & $6(2)$ & $12(4)$ & \multirow[t]{4}{*}{0.821} \\
\hline High School & $70(23.3)$ & $67(22.3)$ & 137(45.7) & \\
\hline University/College education & $54(18)$ & $71(23.7)$ & $125(41.7)$ & \\
\hline Postgraduate studies & $14(4.7)$ & $12(4)$ & $26(8.6)$ & \\
\hline \multicolumn{5}{|l|}{ Work status } \\
\hline Housewife & $64(21,3)$ & $63(21)$ & $127(42.3)$ & \multirow[t]{4}{*}{0.398} \\
\hline Public sector & $20(6.7)$ & $34(11.3)$ & $54(18)$ & \\
\hline Private sector & $36(12)$ & $40(13.3)$ & $76(25.3)$ & \\
\hline Self-employed & $24(8)$ & $19(6.3)$ & $43(14.3)$ & \\
\hline \multicolumn{5}{|l|}{ Gravida } \\
\hline Primigravida & $86(28.7)$ & $69(23)$ & $144(48)$ & \multirow[t]{2}{*}{0.034} \\
\hline Multigravida & $58(19.3)$ & $87(29)$ & $156(52)$ & \\
\hline \multicolumn{5}{|l|}{ Marital Status } \\
\hline Married & $116(38,7)$ & $147(49)$ & $263(87,7)$ & \multirow[t]{4}{*}{0.002} \\
\hline Single & $23(7,7)$ & $9(3)$ & $32(10,7)$ & \\
\hline Divorced & $4(1,3)$ & $0(0)$ & $4(1,3)$ & \\
\hline Widow & $1(0,3)$ & $0(0)$ & $1(0.3)$ & \\
\hline \multicolumn{5}{|l|}{ Pregnancy } \\
\hline Planned & $67(22.3)$ & $99(33)$ & $144(48)$ & \multirow[t]{2}{*}{0.003} \\
\hline Unplanned & $77(25.7)$ & $57(19)$ & $156(52)$ & \\
\hline \multicolumn{5}{|l|}{ Mode of birth } \\
\hline Vaginal birth & $78(26)$ & $86(28.7)$ & $164(54.7)$ & \multirow[t]{2}{*}{0.910} \\
\hline Cesarean section & $66(22)$ & $70(23.3)$ & 136(45.3) & \\
\hline
\end{tabular}

partner was associated with an increased likelihood that a woman continued to smoke throughout her pregnancy $\left(\mathrm{X}^{2}=14.62 ; \mathrm{df}=1 ; p<0.001\right)$.

\section{Depressive symptoms and smoking status}

The mean EPDS score for current tobacco users was 9.72 (SD = 6.280; Std Error Mean 0.523) and for nonsmokers was 8.044 (SD =5.178; Std Error Mean 0.414). The non-smokers group included women who had never smoked or stop smoking before pregnancy and those who quit during pregnancy. Smokers reported significantly higher levels of depressive symptomatology than non-smokers [Levene's Test for equality of variances and homogeneity was calculated $(F=43.059, \quad P=0.0005) \quad(t=2.403 \quad \mathrm{df}=298 \quad$ Sig. $\quad(2-$ tailed) $=0.0005$ ] (Fig. 2).

\section{Maternal health behavior and attitudes regarding smoking}

Fetal health was a critical reason for pregnant women to quit smoking, and most of the participants who quit chose to do this when they found out they were pregnant (Fig. 3). The majority of participants who quit were aware of the threat of smoking to fetal 


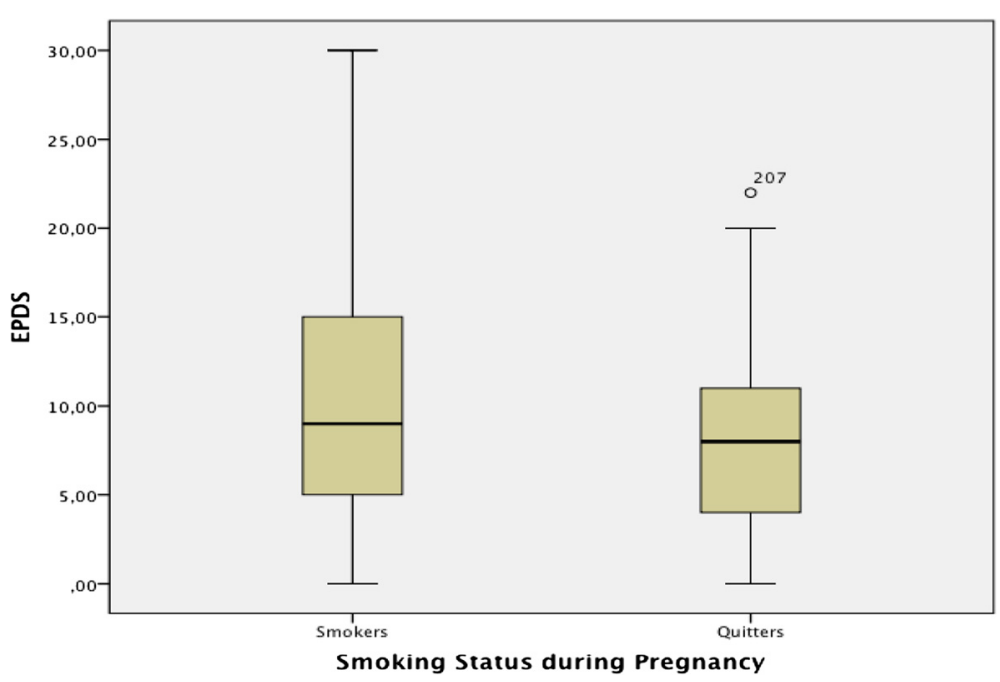

Fig. 2 Smoking Status and Depressive symptomatology

health $(n=208,84.3 \%)$. Of the 119 (83.3 \%) women who tried to reduce or quit smoking because of their pregnancy 64 women $(45.1 \%)$ succeeded and 55 $(38.7 \%)$ continued to smoke during pregnancy. A small proportion of women $(2.7 \%)$ reported that they did not understand that smoking was not recommended during pregnancy because of the high level of risk to fetal health (Table 2).

\section{Passive smoking}

Table 3 shows the exposure of the participants to passive smoking. Forty-two percent of participants lived with a partner who smoked; $13.5 \%$ of the participants lived with relatives who smoked; $9.7 \%$ were exposed to smoke in their work environment; and $34.7 \%$ reported being regularly exposed to second hand smoke in restaurants. Among the participants whose partners were smokers,

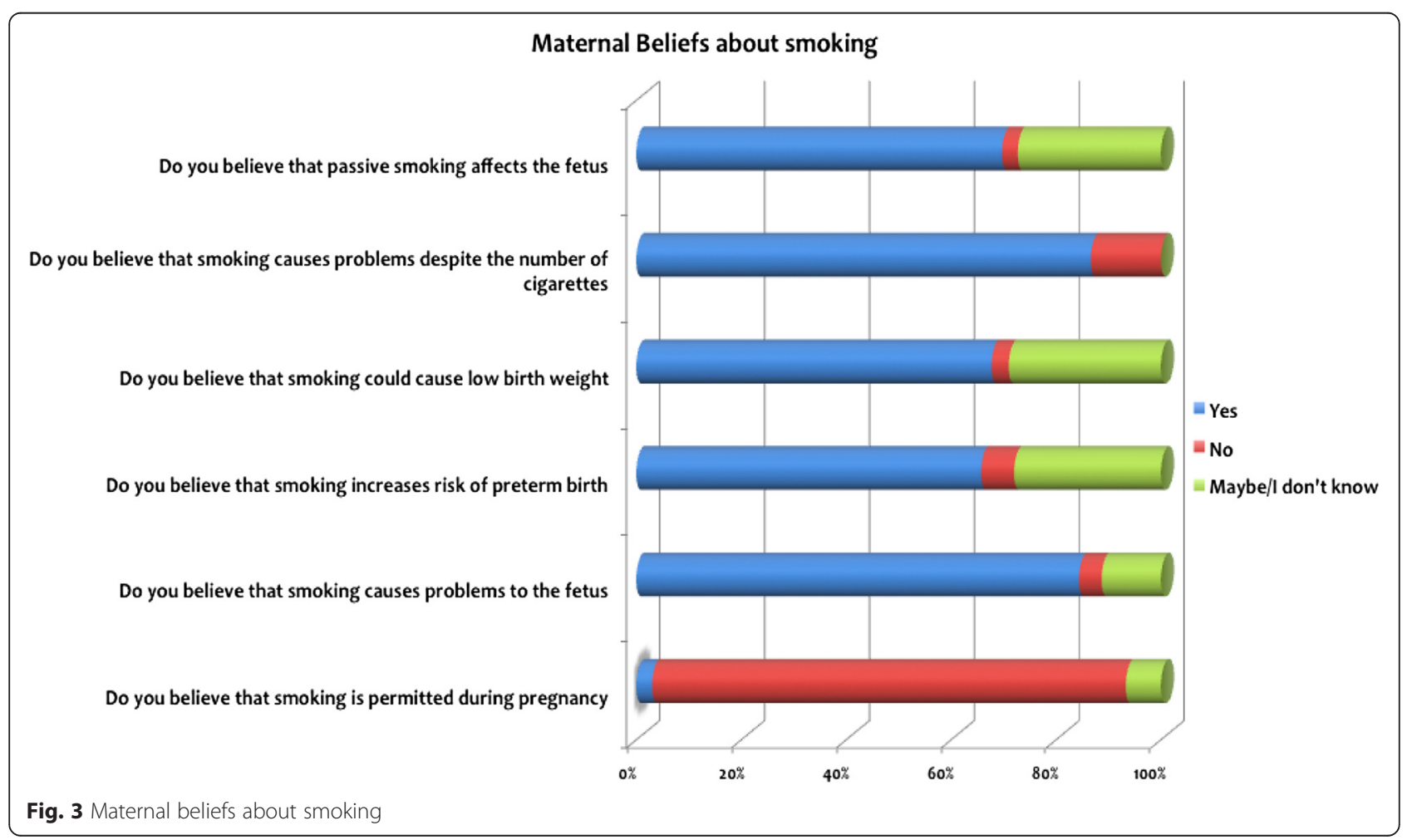


Table 2 Maternal perceptions and attitudes about smoking

\begin{tabular}{|c|c|c|c|c|}
\hline & \multicolumn{4}{|c|}{ Smoking status during pregnancy } \\
\hline & Smokers women $n(\%)$ & Non-smokers women $n(\%)$ & All women total $n(\%)$ & $P$ value \\
\hline \multicolumn{5}{|c|}{ Did you try to reduce or quit because of pregnancy? } \\
\hline Yes & $55(38.7)$ & $64(45.1)$ & $119(83.3)$ & \multirow[t]{2}{*}{$>0.001$} \\
\hline No & 19 (13.4) & $4(2.8)$ & $23(16.2)$ & \\
\hline \multicolumn{5}{|c|}{ Do you believe that smokingis permitted during pregnancy? } \\
\hline Yes & $5(1.7)$ & $3(1)$ & $8(2.7)$ & \multirow[t]{2}{*}{$>0.001$} \\
\hline No & $63(21.1)$ & $208(69.6)$ & $271(90.7)$ & \\
\hline \multicolumn{5}{|c|}{ Do you believe that smoking causes problems to the fetus? } \\
\hline Yes & $44(14.7)$ & $208(84.3)$ & $252(99)$ & \multirow[t]{2}{*}{$>0.001$} \\
\hline No & $11(3.7)$ & $2(9.6)$ & $13(13.3)$ & \\
\hline \multicolumn{5}{|c|}{ Do you believe that smoking causes problems despite the number of cigarettes? } \\
\hline Yes & $54(18.2)$ & $203(68.4)$ & $257(86.6)$ & \multirow[t]{2}{*}{$>0.001$} \\
\hline No & $24(8.1)$ & $16(5.4)$ & $40(13.5)$ & \\
\hline \multicolumn{5}{|c|}{ Do you believe that passive smoking affects the fetus? } \\
\hline Yes & $38(12.7)$ & $170(56.9)$ & $208(69.6)$ & \multirow[t]{2}{*}{$>0.001$} \\
\hline No & $6(2)$ & $3(1)$ & $9(3)$ & \\
\hline
\end{tabular}

$15.8 \%$ were active smokers and $26.3 \%$ non-smokers. (Figs. 4 and 5).

\section{Discussion}

Our study has identified that the initial rate of tobacco use among pregnant women sampled was higher than that of the general population of women in Greece in the same age range (3.7\% of women aged 18-34 smoke in Greece as reported in recent studies) [4, 5]. Addressing smoking in women who are considering pregnancy and targeting women in early pregnancy is a key public health priority for Greece if maternal and infant health outcomes are to be improved. Based on our findings, approximately $73.7 \%$ of women chose not to smoke during pregnancy with $21.7 \%$ reporting quitting in association with their pregnancy. Among woman who continued to smoke during pregnancy, just over half were unable to stop smoking, a quarter did not want to and a small number of women contended they did not believe it was essential, with significant differences in terms of impact of smoking on development of fetal health issues and newborn health problems.
Another criterion that we took into account and on which there was also a statistically significant difference, was the smoking status of the partner $[2,8,23]$. Previous studies which have investigated smoking in pregnancy have also reported that women who did not quit smoking during their pregnancy typically had family members, who were smokers, had partners who smoked, or lived with relatives who smoked $[2,11,12]$. Partners play an important role in influencing women's smoking behaviour in the perinatal period, and their support (or lack of support) can be an important barrier or facilitator to quitting $[2,8,23]$. A partner who continues using tobacco throughout a woman's pregnancy is a significant predictor of the current smoking status of the pregnant woman [2, 8, 23]. Moreover, maternal passive smoke exposure during pregnancy has also been shown to have adverse effects on fetal health [8]. Second hand smoke (SHS) exposure during pregnancy is associated with multiple health concerns in the perinatal period including preterm birth, bronchopulmonary dysplasia, wheezing and asthma [8, 23-26].

Table 3 Women's passive smoking exposures during pregnancy

\begin{tabular}{|c|c|c|c|c|}
\hline & \multicolumn{2}{|c|}{ Smoking status during pregnancy } & \multirow[b]{2}{*}{ Total $n(\%)$} & \multirow[b]{2}{*}{$P$ value } \\
\hline & Smokers women $n(\%)$ & Non-smokers women $n(\%)$ & & \\
\hline \multicolumn{5}{|l|}{ Sources of passive smoking } \\
\hline Partner & $41(15.8)$ & $68(26.3)$ & $109(42.1)$ & $>0.001$ \\
\hline Other relatives & $14(5.4)$ & $21(8.1)$ & $35(13.5)$ & $>0.001$ \\
\hline Work & $5(1.9)$ & $20(7.7)$ & $25(9.7)$ & $>0.001$ \\
\hline Other social places (restaurants, cafes etc.) & $13(5)$ & $77(29.7)$ & $90(34.7)$ & $>0.001$ \\
\hline
\end{tabular}




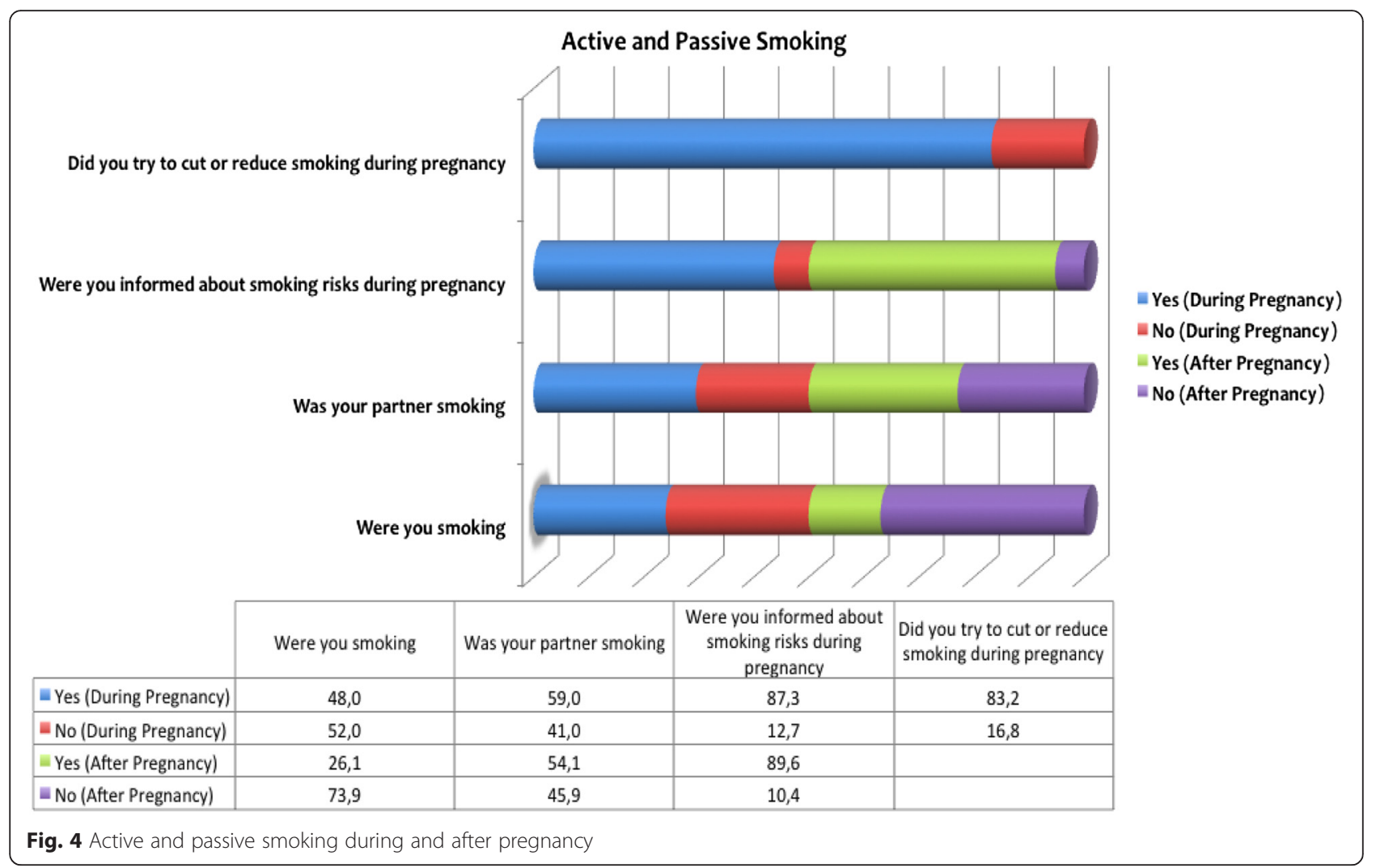

In our study, despite the high level of awareness that pregnant smokers generally demonstrated about risks to the health of their infants as a consequence of their reluctance to quit smoking, only one third of participants were successful in quitting [2]. Based on our findings, even in cases where women managed to quit smoking or reduce their smoking in pregnancy, they continued to be exposed to passive smoke. Moreover, this occurred either as a consequence of the smoking behavior of their partners and other family members, or as a result of being in social places, such as restaurants [2, 8, 23-26]. In line with previous study findings, our study also found that the two most prominent factors influencing the exposure of women to passive smoking were dining at restaurants (41.6\%) and having a partner who smoked (35.9 \%) [2, 8, 23-26]. Having a partner who does

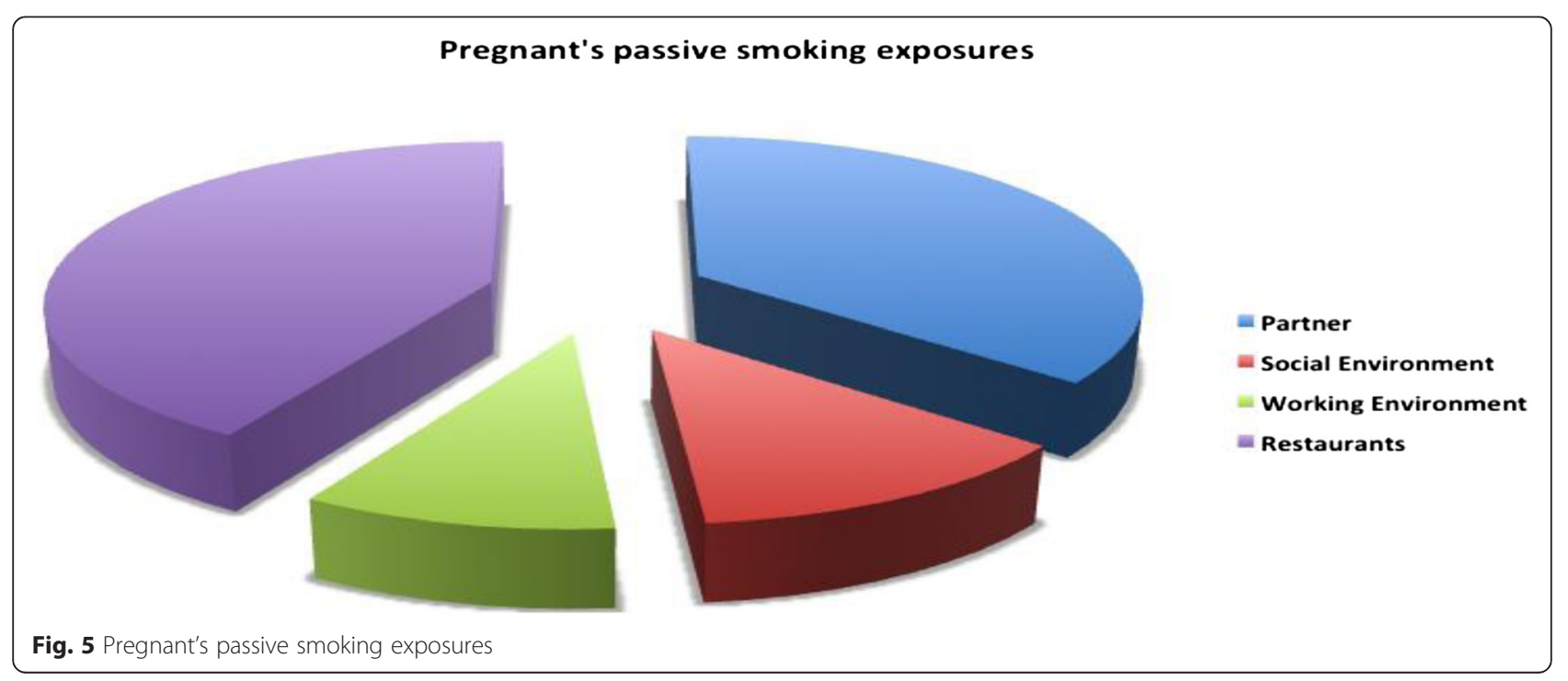


not smoke or who quits when the woman becomes pregnant is clearly of benefit to support a pregnant women's attempts to avoiding contact with passive smoking [2, 8, 23-26].

Although in our study benefits to infant health did not appear to be a motivating factor for other family members to quit smoking, infant health was the most critical reason for pregnant women to quit. Specifically, most of the quitters in our study stopped smoking as soon as their pregnancy was confirmed. It has previously been found that specific psychosocial interventions targeting smoking cessation can increase the number of women who stop smoking in pregnancy, and subsequently reduce low birth weight and preterm births [27]. It is therefore essential that pregnant women, their partners and close relatives are educated on the health risks of active and passive smoking and how these could affect fetal and infant health as well as their own health [2, 8, 23-26, 28]. Moreover, the parents' social support network, including close family members should be involved in supporting smoke-free environments in spaces shared by the newborn. Strategies for successfully engaging families during the perinatal period should be adopted by community based health professionals including community midwives. Health workers should assist women and their families with addressing SHS exposure during the perinatal period by supporting home smoking bans and reducing infant contact with smokers.

In the current study, most pregnant smokers claimed to have actively tried to quit during their pregnancy but unfortunately just over half did not succeed. A possible reason could be that compared to other quitters, pregnant smokers generally had a longer history of smoking $[2,27]$. Furthermore, when advising on quitting, motivational and behavioral support should be provided in parallel with easy access to smoking cessation clinics [27]. It would be also beneficial if this service could be provided in the same maternity hospital or in the community health center.

Whether or not a pregnancy was desired and planned, was also a factor that seemed to affect the willingness of pregnant smokers to quit in our study. Women with planned pregnancies were half as likely to be smokers just before pregnancy, and more likely to give up or reduce the volume of cigarettes as pregnancy progressed. However, unplanned pregnancies had $24 \%$ increased odds of low birth weight and prematurity, compared to planned pregnancies independent of smoking status [17].

Recent studies have reported a number of psychosocial differences between smokers and non-smokers during pregnancy and the postnatal period [29-31]. In our study, women who smoked had significantly higher levels of depressive/anxiety symptoms (Fig. 2) than non- smokers as assessed using the EPDS scale, although caution should be applied to these findings which could reflect women's experiences of transitory psychological symptoms and/or changes in their functioning and mental state as a normal response to the pregnancy and birth experience. Maternal anxiety and stress may inhibit smoking cessation during pregnancy and promote a relapse after pregnancy in women who have achieved abstinence [30]. Smoking cessation is correlated with depressive symptomatology and should be supported under medical guidance among those smokers who are identified as having mental health symptoms. Community midwives were most likely to provide smoking cessation advice in the study by McCurry et al. 2002 [32]. Moreover, counseling by midwives and healthcare staff were found to significantly reduce the volume of smoking during pregnancy and consequently boost an increase in birth weight $[1,27]$. Thus, specific training of community midwives in smoking cessation interventions is needed in order to develop their capability and capacity to provide appropriate and tailored support to pregnant smokers and reduce relapse rates during the postnatal period. In a study from the west of Scotland the development of a home-based midwifery intervention program to support young pregnant smokers to quit was found to be a promising approach to engage young pregnant smokers to help them quit. Local obstetricians and midwives were found to be very willing to support this approach [33].

Smoking during pregnancy not only impacts on the woman's health, but also on the health of her unborn child. Partners and families of pregnant women should be made aware of this risk and encouraged to participate in smoking cessation programs in order to enhance efforts and quitting results. There is evidence that stopping smoking as early as possible during the pregnancy can reduce the above mentioned risks [34, 35]. Group interventions that include health education information about the risks of smoking and advice to quit, are highly recommended during the perinatal period for smoking cessation support or advice on how to make this change [27]. Women who have had a smoke free pregnancy should be offered help to remain smoke free after birth $[34,35]$, given that women who quit smoking during pregnancy remain a high-risk group for smoking relapse during the postpartum period [36].

This study had limitations which should be considered. First, maternal smoking status was assessed based on retrospective self-report and without any further clinical assessment. Secondly, we did not follow women up beyond the first 3 days postnatally to assess if pregnant quitters returned to active smoking and women were not routinely asked in early pregnancy about their smoking status in both maternity settings. Moreover, only 
women who lived in urban areas were able to access the limited free smoking cessation support services offered (mostly in teaching hospitals), if they wanted to quit. As this was a study relevant to perinatal smoking cessation services in Greece, findings may not be not applicable for countries where perinatal smoking cessation services have already been implemented.

Nevertheless, smoking cessation services provided by qualified personnel should be routinely offered in maternity units in Greece. It was apparent in our population that although advice was offered, most pregnant women were unaware or did not know how to access the smoking cessation clinics, which were based in the general hospitals. Although in Greece smoking is banned in public places, there are currently no effective ways of implementing the law. Significant aspects of exposure to passive smoking, such as smoking in cars when children are present, are underestimated and not banned.

The study sample only included participants who gave birth in a public hospital and excluded women who gave birth in private hospitals or at home. However, efforts were made to recruit a representative sample although it should be noted that the rapid socio-economic changes over the last three decades in Greece, have resulted in a relatively homogenous maternal population. Of note is that the majority of women who use public maternity hospitals are routinely transferred to units in Athens for the birth and more specifically to the two large metropolitan university hospitals included in our study. Despite these limitations our sample size is considered satisfactory for statistical analysis.

Other study limitations included the lack of blinding of the midwife researcher to the smoking status of participants which could have potentially resulted in observer bias. Furthermore, there were inherent difficulties due to the low literacy level of women in using a Likert response format. It is possible that other characteristics of maternal smoking behavior corresponded to the differences in risk perceptions and smoking attitudes between smokers and quitters. In this study, we relied on retrospective maternal reports of smoking behavior and recall bias may also have impacted our findings.

The study focused primarily on a potential association between depressive and anxiety symptoms as assessed using the EPDS and maternal active and passive smoking. The EPDS was used in this study because it is a widely administered research tool and no other validated tools are currently available for screening maternal depressive and anxiety symptomology in the Greek language. An EPDS cut-off point of 8/9 was used for screening purposes, in which sensitivity is higher than specificity, in order to detect more potential cases [22].

As only sociodemographic and perinatal variables were assessed as potential confounding factors it is possible that there are other biological and environmental confounding variables which were not detected in this study.

\section{Conclusion}

In this study considerably high rates of tobacco use were reported in the first trimester of pregnancy. Most women chose to stop smoking although there were high levels of exposure to passive smoking. Perceptions of fetal health risks and attitudes towards smoking during pregnancy were critical prognostic factors of the antismoking behaviors of pregnant women in the study sample. Our data supports the importance of ensuring that pregnant women, their partners and close relatives are educated on the health risks of active and passive smoking and how these could have an adverse effect on birth and other health outcomes of women infants. Smokefree environments are necessary to promote perinatal maternal and infant health. There is an emerging need to highlight the international aspects of this critical public health issue.

\section{Competing interests \\ The authors declare that they have no competing interests.}

\section{Authors' contributions}

All authors contributed to the design of the study. W was responsible for the conception of the study and overall supervision of the data collection and analysis, the interpretation of the results, and manuscript preparation. W and $A D$ was responsible for literature search, the interpretation of the results, and writing of the manuscript. W, EP and MT participated in the development of the study protocol, data collection, and analysis. W, AD, MT, EP, DB, SP, KL and $\mathrm{PK}$ reviewed and edited all drafts of the manuscript. All authors have read and approved of the final manuscript.

\section{Acknowledgements}

The authors would like to thank Dr Constantine Vardavas for fruitful discussion on the importance of smoking cessation for the women's health that informed the background to the study, and to express their gratitude to Dr Nikolaos Tsopelas for his stimulating insights. We acknowledge the contributions of the research assistants namely: Voula Giaxi, Alexandra Tsoukaraki, Eleni Zeberligkou, Kalliopi Dritsakou and Katerina Sgartsou and thank the postpartum women who participated in this study. Debra Bick is supported by the National Institute for Health Research (NIHR) Collaboration for Leadership in Applied Health Research and Care South London at King's College Hospital NHS Foundation Trust. The views expressed are those of the author[s] and not necessarily those of the NHS, the NIHR or the Department of Health.

\section{Author details}

${ }^{1}$ Department of Midwifery, Technological Educational Institution of Athens, Athens, Greece. ${ }^{2}$ GAIA Maternity Hospital, Athens, Greece. ${ }^{3}$ King's College London, Florence Nightingale Faculty of Nursing and Midwifery, London, UK. ${ }^{4}$ Division of Prevention and Rehabilitation, University of Ottawa Heart Institute \& Faculty of Medicine, University of Ottawa, Ottawa, ON, Canada. ${ }^{5}$ Department of Critical Care and Pulmonary Services, University of Athens Medical School, Evangelismos Hospital, Athens, Greece.

Received: 10 November 2015 Accepted: 29 March 2016

Published online: 05 April 2016

References

1. Cope GF, Nayyar P, Holder R. Feedback from a point of care test for nicotine intake to reduce smoking during pregnancy. Ann Clin Biochem. 2003;40:674-9. 
2. Lai MC, Chou FS, Yang YJ, Wang CC, Lee MC. Tobacco use and environmental smoke exposure among Taiwanese pregnant smokers and recent quitters: risk perception, attitude, and avoidance behavior. Int J Environ Res Public Health. 2013:10:4104-16.

3. Lawrence W, Haslam C. Smoking during pregnancy where next for stage-based interventions? J Health Psychol. 2007:12(1):159-69.

4. Vardavas Cl, Chatzi L, Patelarou E, Plana E, Sarri K, Kafatos A, Koutis AD, Kogevinas M. Smoking and smoking cessation during early pregnancy and its effect on adverse pregnancy outcomes and fetal growth. Eur J Pediatr. 2010;169:741-8.

5. Vardavas Cl, Patelarou E, Chatzi L, Roumeliotaki T, Sarri K, Murphy S, Koutis A, Kafatos AG, and Kogevinas M. Factors associated with active smoking, quitting, and secondhand smoke exposure among pregnant women in Greece. J Epidemiol. 2010;20(5):355-62.

6. Pallotto EK, Kilbride HW. Perinatal outcome and later implications of intrauterine growth restriction. Clin Obstet GynecolS. 2006;49:257-69.

7. Nordentoft M, Lou HC, Hansen D, Nim J, Pryds O, Rubin P, Hemmingsen R Intrauterine growth retardation and premature delivery: the influence of maternal smoking and psychosocial factors. Am J Public Health. 1996;86: 347-54

8. Leonardi-Bee J, Britton J, Venn A. Second hand smoke and adverse fetal outcomes in non smoking pregnant women: a meta-analysis. Pediatrics. 2011;127:734-41.

9. Miyake $Y$, Tanaka K, Arakawa M. Active and passive maternal smoking during pregnancy and birth outcomes: the Kyushu Okinawa maternal and child health study. BMC Pregnancy Childbirth. 2013;13:157.

10. Ortendahl M, Näsman P. Perception of smoking-related health consequences among pregnant and non-pregnant women. Am J Addiction. 2007;16:521-7.

11. Haslam C, Draper ES. A qualitative study of smoking during pregnancy. Psychol, Health Med. 2001;6:95-9.

12. Penn $G$, Owen $L$. Factors associated with continued smoking during pregnancy: analysis of socio-demographic, pregnancy and smoking-related factors. Drug Alcohol Rev. 2002;21:17-25.

13. Jaddoe WW, Troe EJ, Hofman A, Mackenbach JP, Moll HA, Steegers EA, Witteman JC. Active and passive maternal smoking during pregnancy and the risks of low birth weight and preterm birth: the Generation R Study. Paediatr Perinat Epidemiol. 2008:22:162-17.

14. Steyn $K$, de Wet $T$, Saloojee $Y$, Nel H, Yach D. The influence of maternal cigarette smoking, snuff use and passive smoking on pregnancy outcomes: the birth to ten studies. Paediatr Perinat Epidemiol. 2006;20:90-9

15. Shih SF, Chen L, Wen CP, Yang WC, Shih YT. An investigation of the smoking behaviors of parents before, during and after the birth of their children in Taiwan. BMC Public Health. 2008:8:67.

16. Samet JM, Yoon SY. Gender, women, and the tobacco epidemic. Manila: World Health Organization; 2010.

17. Flower A, Shawe J, Stephenson J, Doyle P. Pregnancy planning, smoking behavior during pregnancy, and neonatal outcome: UK millennium cohort study. BMC Pregnancy and Childbirth. 2013;13:238.

18. Cox J, Holden M, Sagovsky R. Detection of postnatal depression: development of 10-item Edinburgh Postnatal Depression Scale. Br J Psychiatry. 1987;150:782-6.

19. Harris $B$, Huckle $P$, Thomas $R$, et al. The use of rating scales to identify post-natal depression. Br J Psychiatry. 1989;154:813-7.

20. Henshaw C, Foreman D, Cox J. Postnatal blues: a risk factor for postnatal depression. J Psychosom Obstet Gynaecol. 2004;25(3-4):267-72.

21. Beck AT, Ward CH, Mendelson M, Mock J, Erbaugh J. An inventory for measuring depression. Arch Gen Psychiatry. 1961;4(6):561-71.

22. Vivilaki VG, Dafermos V, Kogevinas M, Bitsios P, Lionis C. The Edinburgh postnatal depression scale (EPDS): translation and validation for a Greek sample. BMC Public Health. 2009:9:329.

23. El-Mohandes AA, Kiely M, Blake SM, Gantz MG, El-Khorazaty MN. An intervention to reduce environmental tobacco smoke exposure improves pregnancy outcomes. Pediatrics. 2010;125:721-8.

24. Blaakman SW, Borrelli B, Wiesenthal EN, et al. Secondhand smoke exposure reduction after NICU discharge: results of a randomized trial. Acad Pediatr. 2015. http://dx.doi.org/10.1016/j.acap.2015.05.001.

25. Wagijo, et al. Reducing tobacco smoking and smoke exposure to prevent preterm birth and its complications. Paediatr. Respir. Rev. (2015), http://dx. doi.org/10.1016/j.prrv.2015.09.002
26. Mantziou V, Vardavas Cl, Kletsiou E, Priftis KN. Predictors of childhood exposure to parental secondhand smoke in the house and family car. Int J Env Res Public Health. 2009;6:433-44.

27. Chamberlain C, O'Mara-Eves A, Oliver S, Caird JR, Perlen SM, Eades SJ, Thomas J. Psychosocial interventions for supporting women to stop smoking in pregnancy. Cochrane Database of Systematic Reviews 2013, Issue 10. Art. No.: CD001055. doi:10.1002/14651858.CD001055.pub4

28. Gharaibeh H, Haddad L, Alzyoud S, El-Shahawy O, Abu Baker N, Umlauf M Knowledge, attitudes, and behavior in avoiding secondhand smoke exposure among non-smoking employed women with higher education in Jordan. Int J Env Res Public Health. 2011;8:4207-19.

29. Maxson PJ, Edwards SE, Ingram A, Miranda ML. Psychosocial differences between smokers and non-smokers during pregnancy. Addict Behav. 2012;37:153-9.

30. Hauge $L$, Torgersen $L$, Vollrath $M$. Associations between maternal stress and smoking: findings from a population-based prospective cohort study. Addiction. 2012;107(6):1168-73.

31. Ebert LM, Fahy K. Why do women continue to smoke in pregnancy? Women Birth. 2007;20:161-8

32. McCurry N, Thompson K, Parahoo K, O'Doherty E, Doherty AM. Pregnant women's perception of the implementation of smoking cessation advice. Health Educ J. 2002;61(1):20-31.

33. Bryce A, Butler C, Gnich W, Sheehy C, Tappin DM. CATCH: development of a home-based midwifery intervention to support young pregnant smokers to quit. Midwifery. 2009;25:473-82

34. New Zealand Ministry of Health (2014). Background and Recommendation of the New Zealand Guidelines for Helping People to Stop Smoking. Providing stop-smoking support to pregnant and breastfeeding women. June 2014. Available at http://www.health.govt.nz/system/files/documents/ publications/background-recommendations-new-zealand-guidelines-forhelping-stop-smoking-mar15.pdf

35. NICE public health guidance 26 (2010) Quitting smoking in pregnancy and following childbirth. June 2010. http://www.nice.org.uk/guidance/ph26

36. Horta BL, Kramer MS, Platt RW. Maternal smoking and the risk of early weaning: a meta-analysis. Am J Public Health. 2001;91(2):304-7.

\section{Submit your next manuscript to BioMed Central and we will help you at every step:}

- We accept pre-submission inquiries

- Our selector tool helps you to find the most relevant journal

- We provide round the clock customer support

- Convenient online submission

- Thorough peer review

- Inclusion in PubMed and all major indexing services

- Maximum visibility for your research

Submit your manuscript at www.biomedcentral.com/submit 